\title{
SURFACE MODIFIED MAGNETITE NANOPARTICLES: AN EFFECTIVE TOOL FOR THE SEPARATION OF TOXIC METAL IONS AND ORGANIC CONTAMINANTS FROM WASTEWATER
}

\author{
A. Jangra, J. Singh, K. Rani, J. Kumar, P. Kumar and R. Kumar* \\ Department of Chemistry, Kurukshetra University, Kurukshetra-136119, (Haryana) India \\ *E-mail: rameshkumarkuk@gmail.com
}

\begin{abstract}
The last few centuries are witness of a remarkable increase in the trend towards industrialization and this, in turn, has led to a historic rise in many environmental problems. One of the major problems is the discharge of wastewater from industries to various natural water sources including rivers. Generally, the industrial effluents possess heavy metals and other organic pollutants that have adverse effects on the health of human beings and aquatic life. As a remedy to this environmental problem, novel and cost-effective nanoparticles have attracted the attention of researchers. In this context, appropriate surface-modified magnetite nanoparticles are found to be potential agents for wastewater treatment. This is possibly due to their large surface area and superparamagnetic character. Therefore, efforts have been made to prepare the new highly efficient surface tailored magnetite nanoparticles for metal ion removal from wastewater. In this review article, surface modified magnetite nanoparticles and their application to adsorb or remove contaminants from industrial streams were discussed systematically.
\end{abstract}

Keywords: Heavy Metals, Magnetite Nanoparticles, Surface Modification, Wastewater.

(C) RASĀYAN. All rights reserved

\section{INTRODUCTION}

The scarcity of pure water has become a huge problem worldwide due to the water pollution caused by civilization and industrial development ${ }^{1}$. The effluents released from various industries contain various pollutants such as toxic heavy metals, dyes and various other organic compounds like antibiotics and pesticides. These harmful and toxic industrial effluents are being discharged into the rivers causing water pollution. Among these pollutants, heavy metal ions play a major role in water pollution being nonbiodegradable and highly toxic. Heavy metal ions are mainly present in a substantial amount in the processed streams being released from the mining industries, metal-plating and power generation industries. Moreover, industries involved in the manufacture of various electronic devices also aid in water contamination with heavy metal ions ${ }^{2}$. To overcome the harmful effects of heavy metal ions on the health of human beings and other animals, their removal from the effluents has become an urgent necessity. Various methods such as adsorption, ion exchange, membrane filtration, chemical precipitation and electrochemical treatment are used for the removal of contaminants including heavy and toxic metal ions from the wastewater ${ }^{3,4,5}$. However, among these methods, the adsorption method is considered as the most efficient and popular method due to its effectiveness, ease of use, high efficiency and low $\operatorname{cost}^{6}$. Various adsorbents are being used as potential agents for wastewater treatment. However, conventional nanomaterials such as surface-modified magnetite nanoparticles have emerged as the most promising nano adsorbents as these nanoparticles are cost-effective, highly efficient and ecofriendly. Their property of easy separation from water under the influence of the external magnetic field ${ }^{7,8}$ makes them more attractive. In this article, recent developments towards the synthesis of novel surface engineered magnetite nanoparticles for the deduction of metal ions from aqueous solution have been reviewed. Several researchers have already reviewed the preparation, advantages as well as disadvantages of surface tailored magnetite nanoparticles which could be used for various applications ${ }^{9,10,11}$ such as an effective and efficient adsorbent for the removal of contaminants from waste water. ${ }^{12-15}$

Rasayan J. Chem., 13(4), 2266-2273(2020)

http://dx.doi.org/10.31788/ RJC.2020.1346081

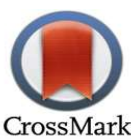




\section{Magnetite $\left(\mathrm{Fe}_{3} \mathrm{O}_{4}\right)$ Nanoparticles}

Some specific nano-sized particles (having size ranging from 1-100 nm) of iron oxide e.g. magnetite nanoparticles show magnetic behavior when the external magnetic field is applied. These magnetite nanoparticles (MNPs) show a unique characteristic termed as superparamagnetism ${ }^{16}$. Superparamagnetism is a phase of zero magnetization when the external magnetic field is removed. These magnetic iron oxide nanoparticles (IONPs) exhibit various other physical and chemical properties also. One of such properties is "large surface area to volume ratio" which makes magnetite nanoparticles a potential nano adsorbent.

\section{Mode of Synthesis of Magnetite Nanoparticles (MNPs)}

Different methods have been reported for the synthesis of magnetite nanoparticles and thus one can choose the appropriate method depending on the requirement of size, morphology, surface modification and magnetic properties of MNPs. Here, few selected methods including co-precipitation, hydrothermal, solvothermal and microemulsion method for the synthesis of magnetite iron oxide nanoparticles (MNPs) have been described. Among all approaches mentioned above; the co-precipitation method is considered as the cost-effective, efficient and simplest way to synthesize MNPs. Briefly, in this method, a mixture of ferric and ferrous salts (molar ratio 1:2) are heated under a nitrogen atmosphere with simultaneous stirring ( $\sim 2200 \mathrm{rpm}$ ) followed by the addition of $\mathrm{NH}_{4} \mathrm{OH}$ to give a black colored precipitate of MNPs possessing superparamagnetic character ${ }^{17}$. This synthetic approach demands careful elimination of oxygen and $\mathrm{pH}$ control. The main advantage of this synthetic approach is a good yield of MNPs. Also, using this method MNPs $\left(\mathrm{Fe}_{3} \mathrm{O}_{4}\right)$ can be synthesized with or without the addition of surfactant. Another popular synthetic approach is the hydrothermal method for the synthesis of MNPs ${ }^{18}$. This method is generally adopted to prepare a single crystal in an autoclave at high pressure. In this method, only one salt of iron i.e. ferrous salt is used as a starting material in contrast to the co-precipitation method. Zhang et al. reported the preparation of $\mathrm{Fe}_{3} \mathrm{O}_{4}$ nanoparticles via hydrothermal synthetic approach and further modified their surface with poly(vinylpyrrolidone) ${ }^{19}$. Next, the solvothermal approach, which is similar to the hydrothermal synthetic approach, is also used to prepare magnetic nanoparticles. Interestingly, in this approach, an organic solvent is preferred contrary to the hydrothermal technique in which water is used. The selection of organic solvent broadens the range of nanomaterials to be prepared by this approach ${ }^{20}$. For example, Jana et al. reported the synthesis of monodispersed magnetite nanocrystals ${ }^{21}$ and cubes upon pyrolysis $\left(\sim 300^{\circ} \mathrm{C}\right)$ of iron oleate in octadecene. The main advantage of this methodology is that it controls the morphology of magnetic nanoparticles. However, in addition to this technique, another important approach, i.e. microemulsion synthesis is also extensively studied. A microemulsion can be defined as a stoichiometric and stable mixture of two immiscible liquids in the presence of an appropriate surfactant. A lot of work has been published on the synthesis of magnetite iron oxide nanoparticles using this method. Zhou et al. reported an oil-in-water emulsion technique to prepare superparamagnetic iron oxide nanoparticles (SPIONs) using cyclohexane as the oil phase. $\mathrm{FeSO}_{4} / \mathrm{Fe}\left(\mathrm{NO}_{3}\right)_{3}$ were used as an iron source while polyoxyethylene isooctyl ether phosphate and nonoxylnol-9-phosphate were used as surfactants ${ }^{22}$. The method has an extra advantage over other methods as MNPs do not get agglomerated during their synthesis.

\section{Applications of Surface Modified Magnetite Nanoparticles (MNPs) in Isolation of Heavy/Toxic Metal Ions and Organic Pollutants from Waste Water}

MNPs are used as an effective tool for the elimination of various pollutants including heavy metal ions and organic contaminants from wastewater. Additionally, suitable coating materials are being used to modify the surface of bare magnetite nanoparticles which not only prevent them from agglomeration but enhance their stability as well. Further, these surface-modified MNPs act as excellent nano adsorbent and can eliminate numerous health-hazardous metal ions including $\mathrm{Cr}^{3+}, \mathrm{Cd}^{2+}, \mathrm{Pb}^{2+}, \mathrm{Ni}^{2+}, \mathrm{Co}^{2+}, \mathrm{Cu}^{2+}$ and $\mathrm{As}^{3+}$ from the contaminated water ${ }^{23}$. The following sections illustrate the role of surface modification of MNPs for enhancing the capability of removal of heavy/toxic metal ions and organic contaminants from wastewater. 


\section{Surface Modification of MNPs for the Removal of Metal Ions from Water}

This section illustrates the importance of surface modification of MNPs for enhancing their capability of removal of heavy/toxic metal ions from wastewater. A lot of work has been published on the surface modification of MNPs using appropriate coating material for their application in the removal of metal ion and other pollutants from the aqueous solution.

\section{Surface Modification of MNPs with Organic Moiety}

Organic compounds of different classes have been used to modify the surface of MNPs. Organosilanes are most relevant compounds used for this purpose, as they form stable \& covalent Si-O-Si bonds with the surface of MNPs. In addition to organosilanes, carboxylic acids, sulfonates and certain amines have been used for surface functionalization of MNPs. Broadly, two categories of organic compounds i.e. polymeric and non-polymeric organic compounds are used for surface modification of MNPs.

\section{Surface Modification of MNPs with Polymeric Compound}

Polymers are largely used as a coating material for surface modification of MNPs as polymers enhance their stability and adsorption capacity. Zhou et al. synthesized chitosan-coated MNPs and further coated them with $\alpha$-ketoglutaric acid ${ }^{24}$. $\alpha$-ketoglutaric acid is a cheap and eco- friendly biological material that improves the capability of chitosan@MNPs to adsorb $\mathrm{Cu}$ (II) from aqueous solutions. It was observed that adsorption isotherm was found to fit better with the Langmuir model rather than the Freundlich model. Mahdavian et al. synthesized acryloyl chloride@3-aminopropyltriethoxysilane@MNPs (AC@APTES@MNPs) and then further modified with acrylic acid (AA) via graft polymerization to form m-PAA (polyacrylic acid). The acrylic acid-modified magnetic nanoparticles were treated with $\mathrm{NaOH}$ to form m-PAA-Na for better adsorption of metal ions ${ }^{7}$. Saturation magnetization was found to be $57.1 \mathrm{emu}$ $\mathrm{g}^{-1}$ for these coated MNPs. A significant increase in the superparamagnetic properties of MNPs was observed with a decrease in the size of MNPs. Further, maximum and minimum adsorption capacities of these functionalized MNPs were calculated at a constant temperature, time and $\mathrm{pH}$ conditions. It was found that m-PAA-Na (salt of acrylic acid modified AC@APTES@MNPs) exhibited a high tendency of removal of $\mathrm{Pb}$ (II) and $\mathrm{Cd}(\mathrm{II})$ ions at high $\mathrm{pH}$ and temperature. Copper is the most common pollutant found in industrial wastewater. Yuwei et al. reported the synthesis of chitosan@ $\mathrm{Fe}_{3} \mathrm{O}_{4}$ for the removal of $\mathrm{Cu}(\mathrm{II})$ ions ${ }^{25}$ from water. The value of saturation magnetization and the maximum adsorption capacity of

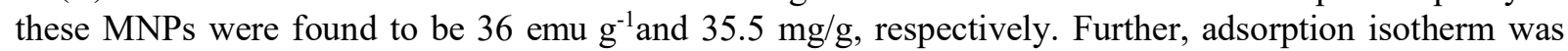
found to be closer to the Langmuir model. It was found that more than $90 \%$ of $\mathrm{Cu}(\mathrm{II})$ ions could be eluted using chitosan modified MNPs. Chou et al. synthesized the poly(amidoamine) (PAMAM) dendrimers conjugated MNPs for the removal of $\mathrm{Zn}$ (II) from aqueous solutions ${ }^{26} . \mathrm{Zn}$ (II) adsorption was found to be $\mathrm{pH}$-dependent and it was found that the maximum amount of $\mathrm{Zn}$ (II) was adsorbed on the surface of GnMNPs (dendrimer conjugated magnetic nanoparticles; where $n$ is dendrimer generation number) at $\mathrm{pH}$ 7.0. Further, these modified MNPs were found to be enough efficient even after ten consecutive cycles of adsorption and desorption suggesting their ability to reuse. Organosilanes are considered suitable adsorbent because of their high capacity of adsorption, non-poisonous nature and biocompatibility. Ge et $a l$. reported the isolation of heavy metal ions including cadmium, mercury, zinc and lead from aqueous solution using MNPs in combination with 3-aminopropyltriethoxysilane (APS) and copolymers of acrylic acid (AA) and crotonic acid (CA) ${ }^{27}$. The results of magnetic studies showed a decrement in the value of saturation magnetization of APS@AA-co-CA@MNPs (52 emu g $\left.\mathrm{g}^{-1}\right)$ \& APS@MNPs (67 emu g $\mathrm{g}^{-1}$ ) as compared to bare MNPs $\left(79 \mathrm{emu} \mathrm{g}^{-1}\right)$. This is obvious due to the non-magnetic nature of APS and AA-coCA. Further, the efficiency of removal of metal ions by these modified MNPs was observed to be nearly the same even after 3-4 cycles of adsorption and desorption. These results led to the conclusion that these polymers are potential adsorbent and thus are an excellent choice for surface modification of MNPs for the removal of metal ions. Inbaraj et al. reported poly- $\gamma$-glutamic acid-coated magnetic iron oxide nanoparticles (PGA@ $\mathrm{Fe}_{3} \mathrm{O}_{4}$ ) for the separation of toxic and heavy metal ions ${ }^{28}$ from the aqueous solution. Saturation magnetization values for bare MNPs and PGA modified MNPs were found to be 70.3 and 61.5 $\mathrm{emu} / \mathrm{g}$, respectively. The effect of $\mathrm{pH}$ on metal ions removal efficiency of these modified MNPs was also studied and maximum removal was observed in $\mathrm{pH}$ range 4 to 8 in deionized water. Badruddoza et al. 
RASĀYAN J. Chem.

Vol. 13 | No. 4 |2266-2273| October - December | 2020

reported the preparation of carboxymethyl- $\beta$-cyclodextrin $(C M-\beta-C D)$, polymer modified MNPs for the separation heavy metals from the industrial wastewater ${ }^{29}$. Ability of $-\mathrm{OH}$ and $-\mathrm{COOH}$ groups (attached to polymer) to bind with metal ions resulted in increased removal efficiency of metal ions by these modified MNPs. A decrement in adsorption capacity of modified MNPs was observed after rise in temperature. Beside this, the adsorption process was found to be exothermic. Maximum value of adsorption capacity was found to be as $64.5,27.7$ and $13.2 \mathrm{mg} / \mathrm{g}$ for $\mathrm{Pb}(\mathrm{II}), \mathrm{Cd}$ (II) \& Ni(II) respectively, at $25^{\circ} \mathrm{C}$. Adsorption capacity of these modified IONPs remained constant even after many cycles of adsorption and desorption. Zare et al. reported the synthesis of poly(aniline-co-m-phenylenediamine)@MNPs (PAMpDA@ $\mathrm{Fe}_{3} \mathrm{O}_{4}$ ) for the removal of heavy metal cations from water samples ${ }^{30}$. A strong interaction was reported between the hydroxyl groups of MNPs and amine groups of a copolymer (PAMpDA) chain. These modified nanocomposites were found to possess high sorption capacity for the heavy metal ions present in wastewater. Various important factors such as contact time, concentration and $\mathrm{pH}$ were taken into account to observe the effect on the metal ion removal efficiency by these surface modified MNPs.

\section{Surface Modification of MNPs with Non-Polymeric Compound}

MNPs modified with non-polymeric compounds are also used for water treatment. A substantial amount of work has been published on the surface modification of MNPs for their utility in metal ion removal from water. Zargoosh et al. reported the synthesis of thiosalicylhydrazide modified magnetite nanoparticles (TSH@MNPs) as an effective tool for the removal of heavy metal ions from the industrial waste water ${ }^{31}$. Thiosalicylhydrazide (TSH) was found suitable material in terms of its remarkable capability to bind with the heavy metal ions. This is obvious as TSH has soft donor sites (nitrogen \& sulfur) for metal ions. Saturation magnetization values of bare MNPs, PAA@MNPs and TSH@PAA@MNPs were 71, 62 and 53 emu g ${ }^{-1}$, respectively. Further, the metal ions removal efficiency of these functionalized MNPs was observed maximum at $\mathrm{pH}$ 4.5-5.

Some metal ions are potentially lethal for humans and other animals. Cadmium and lead metal ions are examples of such metal ions as they can cause bone \& blood-related diseases. So it becomes necessary to remove such metal ions from water. Chen et al. developed sulfonated MNPs $\left(\mathrm{Fe}_{3} \mathrm{O}_{4}-\mathrm{SO}_{3} \mathrm{H}\right)$ for the adsorption of the lead and mercury from the water ${ }^{32}$. It was observed that sulfonated MNPs were found appropriate for the removal of heavy metal cations at all $\mathrm{pH}$ conditions. The effect of the presence of competing ions i.e. $\mathrm{Na}^{+}, \mathrm{Mg}^{2+}$ and $\mathrm{K}^{+}$was also studied.

\section{Surface Modification of MNPs with Inorganic Molecules}

Surface modification of MNPs using inorganic molecules has been reported by many researchers for their use in metal ion removal. Feng et al. reported magnetic hydroxyapatite nanoparticles (MNHAP) as a powerful tool for the removal of toxic metals i.e. cadmium and zinc from the aqueous solutions ${ }^{33}$. Some properties of hydroxyapatite i.e. less cost, high potential of sorption, less solubility in water, and high stability makes it an appropriate material for the surface functionalization of MNPs for the deduction of toxic metal ions. It was observed that the increase in the amount of MNHAP led to an increase in adsorption of heavy metals and a reduction in adsorption was noticed after reaching a maximum value. The effect of $\mathrm{pH}$ on adsorption was also examined and it was observed that amount of adsorption increased with an increase in $\mathrm{pH}(\sim 4$ to 8$)$. Isotherm was found to follow the Langmuir model and kinetics data fitted better with the pseudo second-order reaction. Kumari et al. synthesized mesoporous magnetite nanospheres using a solvothermal method for the removal of heavy metal ions i.e. chromium(VI) and lead(II) from the contaminated water ${ }^{34}$. The magnetization properties of these nanospheres were found to be dependent on the size, morphology, structure, shape, surface disorder and temperature conditions. The efficiency of metal ions removal was found directly related to the initial concentration of adsorbate. Moreover, $\mathrm{Pb}^{2+}$ and $\mathrm{Cr}^{6+}$ were removed significantly on increasing the dose of nanospheres. Bentonite is cheap and natural clay which is used for the removal of wastes from the wate $^{35}$. Farhan reported bentonite-modified magnetic nanoparticles and evaluated their utility in isolation of $\mathrm{Cd}^{2+}$ and $\mathrm{Pb}^{2+}$ ions from aqueous solutions ${ }^{36}$. The author comparatively studied the efficiency of both i.e. natural bentonite and bentonite coated MNPs to remove $\mathrm{Pb}^{2+}$ and $\mathrm{Cd}^{2+}$ from water. The comparative study suggested that bentonite clay modified MNPs were found to be more efficient and eco- friendly for 
RASĀYAN J. Chem.

Vol. 13 | No. 4 |2266-2273| October - December | 2020

the removal of lead and cadmium ions from water. Moreover, it was observed that the $\mathrm{Pb}^{2+}$ was removed more efficiently as compared to $\mathrm{Cd}^{2+}$.

\section{Surface Modification of MNPs with Hybrid Molecules}

Hybrid molecules (i.e. both organic and inorganic molecules together) have been utilized for surface modification of MNPs to enhance their capability to remove metal ions from water. $\mathrm{SiO}_{2}$ is considered as an ideal shell composite to protect the inner core of magnetite nanoparticles. Wang et al. reported aminofunctionalized magnetic nanomaterial having $\mathrm{Fe}_{3} \mathrm{O}_{4} @ \mathrm{SiO}_{2}$ core-shell for the isolation of heavy metals from aqueous solution ${ }^{37}$. These metal ions are removed from the solution by forming a complex with amino groups of functionalized $\mathrm{Fe}_{3} \mathrm{O}_{4} @ \mathrm{SiO}_{2}$ MNPs. Chitosan is one of the most abundant biopolymers found in nature and is used as an effective adsorbent for the removal of heavy metal ions ${ }^{38}$. However, to improve the efficiency of metal ions removal from the water, chitosan is used in combination with magnetic $\operatorname{cores}^{39}$. Ren et al. synthesized ethylenediaminetetraacetic acid (EDTA) modified chitosan@ $\mathrm{SiO}_{2} @ \mathrm{Fe}_{3} \mathrm{O}_{4}$ nanoparticles which were used as potential adsorbent for the removal of heavy metal ion from water ${ }^{40}$. It was observed that the metal ion removal efficiency of these modified MNPs increases with an increase in the amount of adsorbent. Mehdinia et al. synthesized amine-functionalized mesoporous silica nanocomposites for the separation of zinc, copper and lead ions from aqueous solutions ${ }^{41}$. Further, the effect of various factors on the adsorption capacity of these surface-modified MNPs was studied and it was found that the metal ions were removed more efficiently at high $\mathrm{pH}$. The adsorption isotherm was found to follow the Langmuir model. Silica is used as a protective shell to improve the chemical stability of nanoparticles in the acidic medium. Mokadem et al. synthesized triazole (trz) modified magnetic nanoparticles having silica core for the removal of $\mathrm{Pb}^{2+}, \mathrm{Cu}^{2+}$ and $\mathrm{Zn}^{2+}$ ions from the aqueous solution ${ }^{42}$. Adsorption of metal ions from water was found maximum at $\mathrm{pH} 5.5$ and $25^{\circ} \mathrm{C}$. It was found that used triazole modified MNPs were regenerated for the next cycle of adsorption by treating them with dilute $\mathrm{HNO}_{3}$.

Table-1: Summarization of Various Coating Material and Mode of Synthesis Used to Remove Heavy Metal Ions

\begin{tabular}{|c|c|c|c|}
\hline S. No. & Coating Material & Mode of Synthesis used & Metal Ion Removed \\
\hline 1. & Chitosan and $\alpha$-ketoglutaric acid & Co-precipitation & $\mathrm{Cu}(\mathrm{II})$ \\
\hline 2. & $\begin{array}{c}\text { Acryloyl } \\
\text { chloride@3- } \\
\text { aminopropyltriethoxysilane } \\
\end{array}$ & Co-precipitation & $\mathrm{Pb}(\mathrm{II})$ and $\mathrm{Cd}(\mathrm{II})$ \\
\hline 3. & Chitosan & $\begin{array}{c}\text { Co-precipitation } \\
\text { followed by } \\
\text { Hydrothermal treatment } \\
\end{array}$ & $\mathrm{Cu}(\mathrm{II})$ \\
\hline 4. & poly(amidoamine) (PAMAM) & Co-precipitation & $\mathrm{Zn}(\mathrm{II})$ \\
\hline 5. & $\begin{array}{c}\text { 3- } \\
\text { aminopropyltriethoxysilane@Acrylic } \\
\text { acid-copolymer-crotonic acid } \\
\text { (APS@AA-co-CA) }\end{array}$ & $\begin{array}{l}\text { Chemical co- } \\
\text { precipitation }\end{array}$ & $\begin{array}{c}\mathrm{Cd}(\mathrm{II}), \mathrm{Zn}(\mathrm{II}), \mathrm{Pb}(\mathrm{II}) \& \\
\mathrm{Hg}(\mathrm{II})\end{array}$ \\
\hline 6. & poly- $\gamma$-glutamic acid (PGA) & Co-precipitation & $\mathrm{Pb}(\mathrm{II}) \& \mathrm{Cd}(\mathrm{II})$ \\
\hline 7. & $\begin{array}{c}\text { Carboxymethyl- } \\
\beta \text {-cyclodextrin }(\mathrm{CM}-\beta-\mathrm{CD})\end{array}$ & Co-precipitation & $\mathrm{Pb}(\mathrm{II}), \mathrm{Cd}(\mathrm{II}) \& \mathrm{Ni}(\mathrm{II})$ \\
\hline 8. & $\begin{array}{c}\text { poly(aniline-co-m-phenylenediamine) } \\
\text { (PAMpDA) }\end{array}$ & Co-precipitation & $\mathrm{Pb}(\mathrm{II}), \mathrm{Cd}(\mathrm{II}) \& \mathrm{Co}(\mathrm{II})$ \\
\hline 9. & Thiosalicylhydrazide (TSH) & Co-precipitation & $\begin{array}{c}\mathrm{Pb}(\mathrm{II}), \mathrm{Cd}(\mathrm{II}), \mathrm{Cu}(\mathrm{II}) \\
\mathrm{Zn}(\mathrm{II}) \& \mathrm{Co}(\mathrm{II})\end{array}$ \\
\hline 10. & Sulfonated & Sol-gel & $\mathrm{Pb}(\mathrm{II}) \& \mathrm{Cd}(\mathrm{II})$ \\
\hline 11. & $\begin{array}{l}\text { Magnetic hydroxyapatite } \\
\text { nanoparticles (MNHAP) }\end{array}$ & Co-precipitation & $\mathrm{Cd}(\mathrm{II}) \& \mathrm{Zn}(\mathrm{II})$ \\
\hline 12. & Mesoporous magnetite nanospheres & Solvothermal & $\mathrm{Cr}(\mathrm{VI}) \& \mathrm{~Pb}(\mathrm{II})$ \\
\hline 13. & Bentonite & Co-precipitation & $\mathrm{Pb}$ (II) \& Cd(II) \\
\hline
\end{tabular}


RASĀYAN J. Chem.

Vol. 13 | No. 4 |2266-2273| October - December | 2020

\begin{tabular}{|c|c|c|c|}
\hline 14. & $\begin{array}{c}\text { Amino-functionalized magnetic } \\
\text { nanomaterial having } \\
\mathrm{Fe}_{3} \mathrm{O}_{4} @ \mathrm{SiO}_{2} \text { core-shell }\end{array}$ & Microemulsion & $\mathrm{Pb}(\mathrm{II}) \& \mathrm{Cd}(\mathrm{II})$ etc. \\
\hline 15. & $\begin{array}{l}\text { Ethylenediaminetetraacetic acid } \\
\text { (EDTA) modified chitosan } @ \mathrm{SiO}_{2}\end{array}$ & Solvothermal & $\begin{array}{c}\mathrm{Pd}(\mathrm{II}), \mathrm{Cu}(\mathrm{II}) \& \\
\mathrm{Cd}(\mathrm{II})\end{array}$ \\
\hline 16. & $\begin{array}{l}\text { Amine-functionalized mesoporous } \\
\text { silica nanocomposites }\end{array}$ & Co-precipitation & $\mathrm{Pb}(\mathrm{II}), \mathrm{Cu}(\mathrm{II}) \& \mathrm{Zn}(\mathrm{II})$ \\
\hline 17. & Triazole (trz) & Co-precipitation & $\mathrm{Pb}(\mathrm{II}), \mathrm{Cu}(\mathrm{II}) \& \mathrm{Zn}(\mathrm{II}$ \\
\hline
\end{tabular}

\section{Removal of Organic Contaminants from Water by Surface Modified MNPs}

Organic contaminants generally include antibiotics and pesticides etc. These are detected worldwide in processed water streams. Magnetite $\left(\mathrm{Fe}_{3} \mathrm{O}_{4}\right)$ nanoparticles are used as nano adsorbent for the removal of such organic pollutants. Zhang et al. used $\mathrm{Fe}_{3} \mathrm{O}_{4}$ nanoparticles ${ }^{43}$ for the adsorption of tetracycline and chlortetracycline (CTC) from water. These magnetic nanoparticles possessed high adsorption capacity for CTC. On the contrary, the low adsorption capacity was observed for ofloxacin and sulfathiazole. Additionally, their adsorption behavior was found to be affected by the concentration of co-existing divalent cations, ion strength as well as the quality of water. The CTC-loaded magnetite nanoparticles might be regenerated using the $\mathrm{H}_{2} \mathrm{O}_{2}$ approach or calcination process. Danaligolu et al. synthesized humic acid and levulinic acid-modified IONPs and used them for the removal of ciprofloxacin ${ }^{44}$ from water. Tian et al. reported the use of hexagonal mesoporous silica (HMS) with magnetic functionalization $\left(\mathrm{Fe}_{3} \mathrm{O}_{4} @ \mathrm{HMS}\right)$ for the removal of well-known pesticide dichloro diphenyl trichloroethane (DDT) from aqueous solution ${ }^{45}$. These $\mathrm{Fe}_{3} \mathrm{O}_{4} @$ HMS materials display high adsorption capacity and fast adsorption rate for DDT. These materials provide a rapid, effective and efficient way to remove DDT from aqueous solutions due to their unique characteristics such as magnetic properties and mesoporous structure.

\section{CONCLUSION}

Water purification by removing the heavy metal ions and other organic pollutants from the wastewater using surface-functionalized MNPs has offered more opportunities as compared to traditional adsorbents. Therefore, researchers are showing much interest to develop novel and more efficient surface-modified MNPs for the removal of contaminants from water. The extra advantage of using surface-modified MNPs over other adsorbents is due to their unique properties like "large surface area to volume ratio" and "superparamagnetic properties". Due to these properties, MNPs have remarkable adsorption capacity and the ability to be reused. Overall, it may be concluded that the surface-modified MNPs have emerged as a promising tool for the removal of metal ions and organic pollutants from the aqueous solution.

\section{ACKNOWLEDGMENT}

Co-authors, Arti Jangra, Jaiveer Singh, Keerti Rani and Jai Kumar are highly thankful to UGC, New Delhi for providing funds in the form of Junior Research Fellowship. The authors are thankful to the Department of Chemistry, Kurukshetra University, Kurukshetra for providing all required research facilities.

\section{Abbreviations}

IONPs: Iron oxide nanoparticles, MNPs: Magnetite nanoparticles, SPIONs: Superparamagnetic iron oxide nanoparticles, AC@APTES@MNPs: Acryloyl chloride@3-aminopropyltriethoxysilane@MNPs, PAMAM: poly(amidoamine), APS: 3-aminopropyltriethoxysilane, AA: Acrylic Acid, CA: Crotonic Acid, CM- $\beta$-CD: $\quad$ Carboxymethyl- $\beta$-cyclodextrin, $\quad \mathrm{PAMpDA} @ \mathrm{Fe}_{3} \mathrm{O}_{4}$ : poly(aniline-co-mphenylenediamine)@MNPs, TSH: Thiosalicylhydrazide, MNHAP: Magnetic hydroxyapatite nanoparticles, EDTA: Ethylenediaminetetraacetic acid, trz: triazole, CTC: Chlortetracycline, HMS: Hexagonal mesoporous silica, DDT: Dichloro diphenyl trichloroethane.

\section{REFERENCES}

1. X.M. Li, G. Xu, Y. Liu and T. He, Nanoscience \& Nanotechnology-Asia, 1(1), 14(2011),DOI: $10.2174 / 2210681211101010014$

2. J. Wang and C. Chen, Biotechnology Advances, 27(2), 195(2009), DOI: 
RASĀYAN J. Chem.

Vol. 13 | No. 4 |2266-2273| October - December | 2020

10.1016/j.biotechadv.2008.11.002

3. F. Fu and Q. Wang, Journal of Environmental Management, 92(3), 407(2011),DOI: 10.1016/j.jenvman.2010.11.011

4. D.W. O' Connell, C. Birkinshaw and T.F. O' Dwyer, Bioresource Technology, 99(15), 6709(2008), DOI: $10.1016 /$ j.biortech.2008.01.036

5. T.A.Kurniawan, G. Chan, W.H. Lo and S.Babel, Chemical Engineering Journal, 118(1-2), 83(2006), DOI: $10.1016 /$ j.cej.2006.01.015

6. A. Stafiej and K. Pyrzynska, Separation and Purification Technology, 58(1), 49(2007),DOI: 10.1016/j.seppur.2007.07.008

7. A.R. Mahdavian and A.S. Mirrahimi, Chemical Engineering Journal, 159(1-3), 264(2010), DOI: 10.1016/j.cej.2010.02.041

8. X. Zhao, L. Lv, B. Pan, W. Zhang, S. Zhang and Q. Zhang, Chemical Engineering Journal, 170(23), 38(2011), DOI: 10.1016/j.cej.2011.02.071

9. F. Gao, Chemistry Select, 4(22), 6805(2019), DOI: 10.1002/slct.201900701

10. S. Gul, S.B. Khan, I.U. Rehman, M. A. Khan and M. I. Khan, Frontiers in Materials, 6, 17(2019), DOI: $10.3389 /$ fmats.2019.00179

11. A. Ali, H. Zafar, I. Zia, A. Haq, A.R. Phull, J.S. Ali and A. Hussain, Nanotechnology, Science and Applications, 9, 49(2016), DOI: 10.2147/NSA.S99986

12. P.N. Dave and L.V. Chopda, Journal of Nanotechnology, 2014 (2014), DOI: 10.1155/2014/398569

13. M.O. Ojemaye, O.O. Okoh and A.I. Okoh, Materials Express, 7(6), 439(2017),DOI: 10.1166/mex.2017.1401

14. J. Yang, B. Hou, J. Wang, B. Tian, J. Bi, N. Wang, X. Li and X. Huang, Nanomaterials, 9(3), 424(2019), DOI: 10.3390/nano9030424

15. F.S.A. Khan, N.M. Mubarak, M. Khalid, R. Walvekar, E.C. Abdullah, S.A. Mazari, S. Nizamuddin and R.R. Karri, Environmental Science and Pollution Research, 1(2015), DOI: 10.1007/s11356-02008711-6

16. W. Jiang, H.C. Yang, S.Y. Yang, H.E. Horng, J.C. Hung, Y.C. Chen and C.Y.Hong, Journal of Magnetism and Magnetic Materials, 283(2-3), 210(2004), DOI: 10.1016/j.jmmm.2004.05.022

17. J. Singh, A. Jangra, J. Kumar, K. Rani and R. Kumar, Rasayan Journal of Chemistry, 13(1), 105(2020), DOI: 10.31788/RJC.2020.1315382

18. R. Fan, X.H. Chen, Z. Gui, L. Liu and Z.Y. Chen, Materials Research Bulletin, 36(3-4), 497(2001), DOI: $10.1016 / \mathrm{S} 0025-5408(01) 00527-\mathrm{X}$

19. Z. Zhang, X. Chen, B. Wang and C.W. Shi, Journal of Crystal Growth, 310(24), 5453(2008), DOI: 10.1016/j.jcrysgro.2008.08.064

20. B. Parkinson, Science, 270(5239), 1157(1995), DOI: 10.1126/science.270.5239.1157

21. N.R. Jana, Y. Chen and X. Peng, Chemistry of Materials, 16(20), 3931(2004), DOI: $10.1021 / \mathrm{cm} 049221 \mathrm{k}$

22. Z.H. Zhou, J. Wang, X. Liu and H.S.O. Chan, Journal of Materials Chemistry, 11(6), 1704(2001), DOI: $10.1039 / \mathrm{b} 100758 \mathrm{k}$

23. S. Singh, K. Barick and D. Bahadur, Journal of Hazardous Materials, 192(3), 1539(2011), DOI: 10.1016/j.jhazmat.2011.06.074

24. Y.T. Zhou, H.L. Nie, C. Branford-White, Z.Y. He and L.M. Zhu, Journal of Colloid and Interface Science, 330(1), 29 (2009), DOI:10.1016/j.jcis.2008.10.026

25. C. Yuwei and W. Jianlong, Chemical Engineering Journal, 168(1), 286(2011),DOI: 10.1016/j.cej.2011.01.006

26. C.M. Chou and H.L. Lien, Journal of Nanoparticle Research, 13(5), 2099(2011),DOI: 10.1007/s1 1051-010-9967-5

27. F. Ge, M.M. Li, H. Ye and B.X. Zhao, Journal of Hazardous Materials, 211-212, 366(2012),DOI: 10.1016/j.jhazmat.2011.12.013

28. B. Inbaraj and B.H. Chen, International Journal of Nanomedicine, 7, 4419(2012),DOI: 10.2147/IJN.S34396

29. A. Badruddoza, Z. Shawon, T. Daniel, K. Hidajat and M.S. Uddin, Carbohydrate Polymers, 91(1), SURFACE MODIFIED MAGNETITE NANOPARTICLES 
RASĀYAN J. Chem.

Vol. 13 | No. 4 |2266-2273| October - December | 2020

322(2013), DOI: 10.1016/j.carbpol.2012.08.030

30. E.N. Zare, M.M. Lakouraj and A. Ramezani, Advances in Polymer Technology, 34(3), 1(2015), DOI: 10.1002/adv.21501

31. K. Zargoosh, H. Abedini, A. Abdolmaleki and M. R. Molavian, Industrial and Engineering Chemistry Research, 52(42), 1494 (2013), DOI: 10.1021/ie401971w

32. K. Chen, H. Junyong, L. Yulian, X. Cai, K.Zhang, T. Liu, Y. Hu, D. Lin, L. Kong and J. Liu, Journal of Colloid and Interface Science, 494, 307(2017), DOI: 10.1016/j.jcis.2017.01.082

33. Y. Feng, J.L. Gong, G.M. Zeng, Q.Y. Niu, H.Y. Zhang, C.G. Niu, J.H. Deng and M.Yan, Chemical Engineering Journal, 162(2), 487(2010), DOI: 10.1016/j.cej.2010.05.049

34. M. Kumari, C.U. Pittman and D. Mohan, Journal of Colloid and Interface Science, 442 120(2015), DOI: $10.1016 /$ j.jcis.2014.09.012

35. A. Mellah and S. Chegrouche, Water Research, 31(3), 621(1997),DOI:10.1016/S00431354(96)00294-1

36. B.S. Al Farhan, International Journal of Nanomaterial Chemitsry, 2(1), 27(2016), DOI: 10.18576/ijnc/020105

37. J. Wang, S. Zheng, Y. Shao, J. Liu, Z. Xu and D. Zhu, Journal of Interface and Science, 349(1), 293(2010), DOI: $10.1016 /$ j.jcis.2010.05.010

38. E. Guibal, Separation and Purification Technology, 38(1), 43(2004),DOI: 10.1016/j.seppur.2003.10.004

39. Y.X. Zhang, X.Y. Yu, Z. Jin, Y. Jia, W.H. Xu, T. Luo, B.J. Zhu, J.H. Liu and X.J. Huang, Journal of Materials Chemistry, 21(41), 16550 (2011), DOI: 10.1039/C1JM12196K

40. Y. Ren, H. Abbood, F. He, H. Peng and K. Huang, Chemical Engineering Journal, 226(15), 300(2013), DOI: $10.1016 /$ j.cej.2013.04.059

41. A. Mehdinia, S. Shegefti and F. Shemirani, Journal of Brazilian Chemical Society, 26(11), 2249(2015), DOI: 10.5935/0103-5053.20150211

42. Z. Mokadem, S. Mekki, S. Saïdi-Besbes, G. Agusti, A. Elaissari and A. Derdour, Arabian Journal of Chemistry, 10(8), 1039(2017), DOI: 10.1016/j.arabjc.2016.12.008

43. D. Zhang, H. Niu, X. Zhang, Z. Meng and Y.Cai, Journal of Hazardous Materials, 192(3), 1088(2011), DOI: 10.1016/j.jhazmat.2011.06.015

44. S.T. Danalığlu, Ş.S. Bayazit, Ö. Kerkez, B.G. Alhogbi, and M. Abdel Salam, Chemical Engineering Research and Design, 123, 259(2017), DOI: 10.1016/j.cherd.2017.05.018

45. H. Tian, J. Li, Q. Shen, H. Wang, Z. Hao, L. Zou and Q. Hu, Journal of Hazardous Materials, 171(13), 459(2009), DOI: 10.1016/j.jhazmat.2009.06.029

[RJC-6081/2020] 